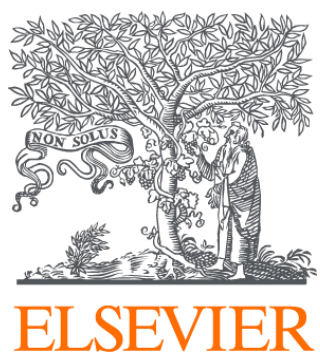

Since January 2020 Elsevier has created a COVID-19 resource centre with free information in English and Mandarin on the novel coronavirus COVID-

19. The COVID-19 resource centre is hosted on Elsevier Connect, the company's public news and information website.

Elsevier hereby grants permission to make all its COVID-19-related research that is available on the COVID-19 resource centre - including this research content - immediately available in PubMed Central and other publicly funded repositories, such as the WHO COVID database with rights for unrestricted research re-use and analyses in any form or by any means with acknowledgement of the original source. These permissions are granted for free by Elsevier for as long as the COVID-19 resource centre remains active. 


\title{
An Emergency Medical Services Transfer Authorization Center in Response to the Toronto Severe Acute Respiratory SYNDROME OUTBREAK
}

\author{
Russell D. MacDonald, MD, MPH, Bruce Farr, Michael Neill, BBA, BHSc, MEd, \\ John Loch, Bruce Sawadsky, MD, Chris Mazza, MD, Karim Daya, BSc, \\ Chris Olynyk, Sandra Chad, BA
}

ABSTRACT

Objective. To describe the rapid development and implementation of an innovative emergency medical services (EMS) command, control, and tracking system to mitigate the risk of iatrogenic spread of severe acute respiratory syndrome (SARS) among health care facilities, health care workers, and patients in Ontario, Canada, as a result of interfacility patient transfers. Methods. A working group of stakeholders in health care and transport medicine developed and implemented a medically based command, control, and tracking center for all interfacility (including acute and long-term care) patient transfers in Ontario, Canada. Development and implementation took place in three distinct but overlapping phases: needs assessment, design and implementation, and expansion and ongoing operations. Results. The needs assessment, design, and implementation were completed in less than 48 hours using existing EMS infrastructure and personnel. The center was successfully handling more than 500 requests for interfacility patient transfer per day within 36 hours of operation and more than 1,100 requests per day within two weeks. Expansion into a new physical space enables 40 staff to process up to 1,500 requests per day. There was no reported spread of SARS resulting from interfacility patient transfers since the center began operation on April 1, 2003, and anecdotal evidence demonstrates it identified up to 13 new SARS cases. The center continues to operate as a part of Ontario's commitment as a result of diligence in transport medicine and infection control, even though no new cases of SARS were reported since June 12, 2003. Further study is needed to determine its overall efficacy at risk mitigation.

Received September 8, 2003, from the Division of Emergency Medicine, Department of Medicine, Faculty of Medicine (RDM, BS, CM), University of Toronto, Toronto, Ontario, Canada; Ontario Air Ambulance Base Hospital Program, Division of Prehospital Care (RDM, BS, CM), Sunnybrook and Women's College Health Sciences Centre, Toronto, Ontario, Canada; and Toronto Emergency Medical Services (BF, MN, JL, KD, CO, SC), Toronto, Ontario, Canada.

Presented at the National Association of EMS Physicians annual meeting, Tucson, Arizona, January 2004.

Address correspondence and reprint requests to: Russell D. MacDonald, MD, Medical Director, Central Region, Ontario Air Ambulance Base Hospital Program, 1120 Finch Avenue West, Suite 405, Toronto, Ontario, Canada M3J 3H7. e-mail: <rmacdonald@ basehospital.on.ca>.

doi:10.1016/j.prehos.2003.12.015
Conclusions. Rapid establishment of an EMS-based command, control, and tracking center is possible in the setting of a public health emergency. In addition to risk mitigation, this type of center could provide syndromic surveillance in real time and provide the earliest indication of a potential threat to public health in acute and long-term care facilities. Key words: SARS; emergency medical services; communication systems; risk management; iatrogenic disease.

PREHOSPITAL EMERGENCY CARE 2004;8:223-231

On November 16, 2002, the first case of a new, atypical pneumonia occurred in Foshan city, Guangdong Province, China. On February 11, 2003, the Chinese Ministry of Health informed the World Health Organization (WHO) of this outbreak, ${ }^{1,2}$ prompting the WHO to issue a global alert about the rapidly progressive atypical pneumonia, referred to as severe acute respiratory syndrome (SARS). ${ }^{3}$ By early March 2003, SARS had spread internationally, via Hong Kong, causing outbreaks in several countries. ${ }^{4}$

The first Canadian death resulting from SARS occurred in Toronto, Ontario, on March 5, 2003..$^{5}$ The index case and her husband were in Hong Kong in late February, staying in the same hotel as a physician from Guangdong Province. A case cluster in Toronto was linked to the index case and a single Toronto hospital in mid-March. ${ }^{6}$ This first cluster included relatives of the index case and health care workers who cared for the index case and her relatives. By late March, a largescale SARS outbreak was under way in the Greater Toronto Area (GTA). The outbreak prompted the government of Ontario to declare a health care emergency, activate the Provincial Operations Center, and require all GTA hospitals to initiate their emergency response plans for an external disaster.

Public health officials investigating the GTA outbreak determined SARS had spread from the index hospital to several other hospitals and health care institutions as a result of, in part, interfacility patient transfers. ${ }^{6,7}$ On March 27, 2003, the Ontario Ministry of Health and Long-Term Care suspended all transfers pending a solution to prevent the spread of SARS by this route. This report describes the rapid development and implementation of an innovative emergency medical 
services (EMS) command, control, and tracking system to mitigate the risk of iatrogenic spread of SARS among health care facilities, health care workers, and patients in Ontario, Canada, as a result of interfacility patient transfers.

\section{Methods}

\section{Setting}

The City of Toronto is Ontario's provincial capital and Canada's largest city, with an urban area of $641 \mathrm{~km}^{2}$ and a resident population of 2.5 million. The GTA includes Toronto and four neighboring regional municipalities with a total resident population of 5.1 million. The Province of Ontario encompasses approximately 1.1 million $\mathrm{km}^{2}$, with a mix of urban, suburban, rural, and remote areas and a population of 12 million.

Emergency medical services in the City of Toronto are provided by Toronto EMS. This municipally and provincially cofunded EMS agency is Canada's largest, with more than 400,000 emergency and 50,000 nonemergency requests for service annually. The Toronto EMS Central Ambulance Communication Center (CACC) coordinates and dispatches EMS requests and is Canada's single largest EMS dispatch center.

On March 30, 2003, two principal authors (RDM, BF) assembled a working group of stakeholders to develop and implement a center to provide medical oversight and command, control, and tracking of interfacility patient transfers involving health care facilities in the GTA. There was an urgent need for this center because medical services are regionalized and interfacility transfers could not be suspended indefinitely. The working group would determine the scope of this new center, develop an oversight plan, and implement it in less than 72 hours. The development and implementation of the interfacility patient transfer center took place in three distinct but overlapping phases: needs assessment, design and implementation, and expansion and ongoing operations.

\section{RESULTS}

\section{Needs Assessment}

The working group defined interfacility patient transfer as any patient movement between health care facilities regardless of mode of transport, but not including transfer home or to a medical appointment outside a health care facility. They also determined that a single center for the entire province was necessary because patient transfers were routinely done between GTA and non-GTA health care facilities. A single center would also facilitate implementation of new government directives and public health guidelines related to the SARS outbreak or any other health care emergency that might arise. This new center would be referred to as the Provincial Transfer Authorization Center (PTAC) and would coordinate, control, and track all interfacility patient transfers in Ontario.

Based on historical data, the working group forecast there would be approximately 500 daily requests within 48 hours of the PTAC's becoming operational. The group also forecast there would be 1,300 requests each weekday and 800 each weekend day within ten days, with peak volumes between 8 AM and 4 PM.

The working group chose to colocate the PTAC with the Toronto EMS CACC at Toronto EMS headquarters. This CACC already coordinated the single largest proportion of patient transfers in Ontario and could expand to all patient transfers in Ontario. Toronto EMS would coordinate staffing and operate the center. There was no time to locate another facility or hire new staff. The Ontario Air Ambulance Base Hospital Program and the Provincial SARS Operations Center would oversee the command and control functions and provide medical oversight. The proposed project timeline is outlined in Table 1.

\section{Design and Implementation}

The working group used the existing categories of SARS exposure (Table 2) established by the provincial SARS Scientific Committee to develop a simple decision tree (Fig. 1) and determine which transfers could be approved. Existing EMS computer-aided dispatch hardware and software could not be modified in the short implementation timeline. As an alternative, the working group designed a paper-based system (Fig. 2) to capture the relevant patient information. The forms would also provide an epidemiologic tool should retrospective contact tracing be necessary.

Communication among the center, health care facilities, central bed and resource registry, and regional CACCs would occur by telephone and facsimile. The working group chose this method because the technology was universally available and end-users were familiar with its use. The working group proposed a web-based application, but the short implementation timeline and limited Internet connectivity in some hospitals made this initially unfeasible. CACCs, ambulances, and EMS crews would communicate using existing methods (radio, pager, and telephone).

To request approval for an interfacility patient transfer, the sending facility would complete a patient transfer authorization form (Fig. 2) and fax it to the PTAC. A paramedic, using the decision algorithm (Fig. 1), would process the request. The transfer would be approved if it met the predetermined criteria. A physician would adjudicate requests that did not meet 
TABLE 1. PTAC Projected Implementation Timeline

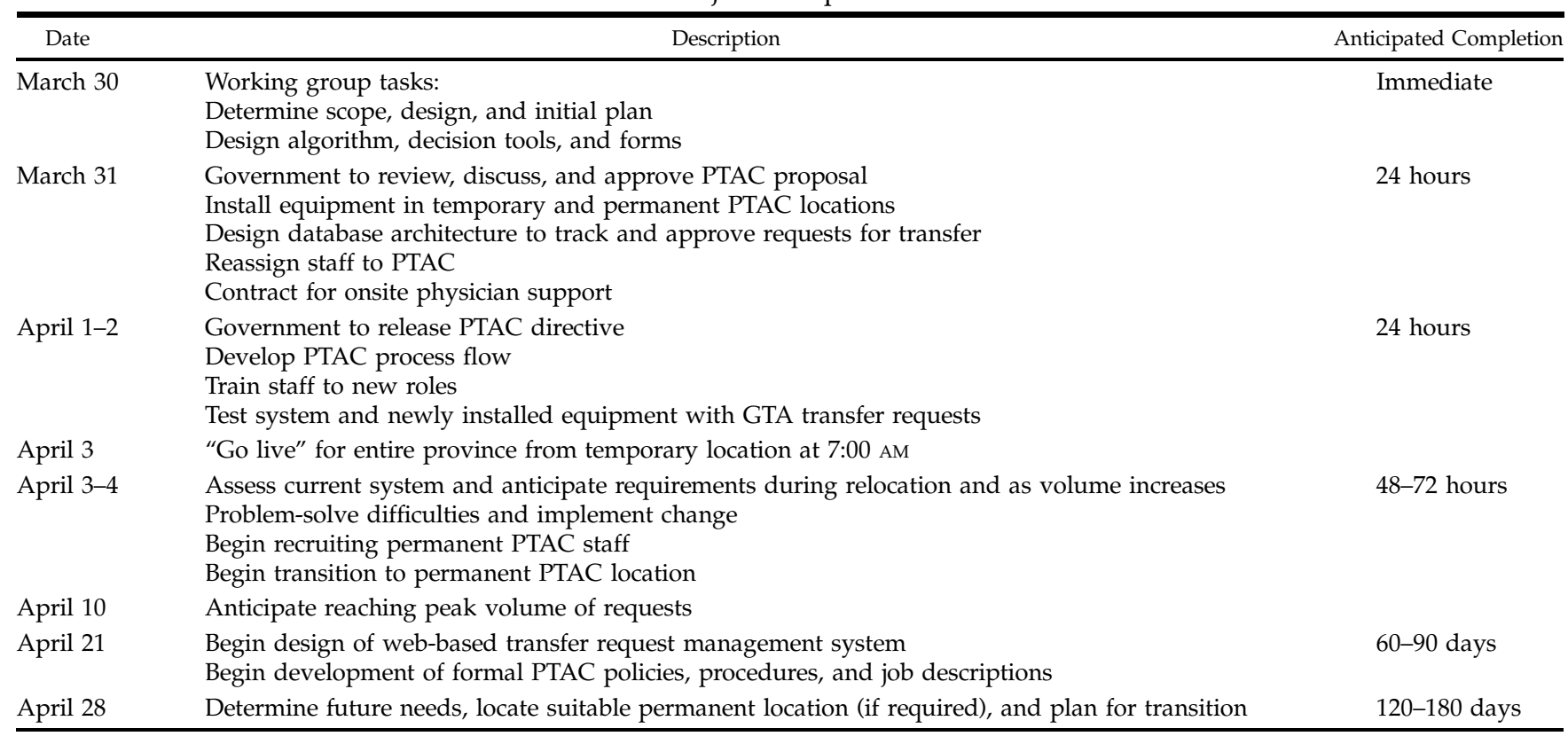

PTAC = Provincial Transfer Authorization Center; GTA = Greater Toronto Area.

criteria. All requests for emergent transfer would be prioritized and receive immediate attention.

If the transfer was approved, a Toronto EMS dispatcher located in the center would book a request for transfers within the city of Toronto. For those transfers outside the city of Toronto, the PTAC would notify the sending institution the transfer is approved. The sending institution would then contact its appropriate regional CACC or local ambulance service provider for these transfers. The regional CACC would dispatch the appropriate ground ambulance and crew in the usual way. Requests for aeromedical transfers would be approved by the center and dispatched by the provincial air transportation coordination center in the usual way.

Requests for emergent transfer as a result of life- and limb-threatening illness or injury would be approved immediately regardless of predetermined criteria. If the criteria were not met, the PTAC physician would contact the receiving facility to ensure all appropriate infection control precautions were in place to prevent possible iatrogenic spread of SARS.

Toronto EMS supervisory staff determined 16 to 20 staff positions were required for the center's initial 48 hours of operation, with an anticipated doubling of staff requirements within seven days. In addition, an onsite physician was required to provide medical backup and adjudication of patient transfer requests that did not meet predetermined criteria. Table 3 lists the initial staff requirements for anticipated peak requests.

Colocating the PTAC at Toronto EMS headquarters permitted sharing of existing staff and communication resources. Colocation required minimal setup because existing telephone and facsimile capabilities could handle the anticipated volume of requests in the first 48 to 72 hours. The center would relocate to a permanent location at Toronto EMS headquarters no later than April 7.

The PTAC proposal and implementation timeline were forwarded to Provincial government on March 31, 2003. It was immediately approved and disseminated as a directive to all Ontario hospitals. The two principal authors (RDM, BF) were then instructed to implement the PTAC proposal immediately. On April 1 at 2:30 PM, the PTAC was operational and began its command, control, and tracking function for all interfacility patient transfers in the Province of Ontario.

Approval, dissemination, and implementation of the PTAC proposal occurred before the necessary space, equipment, and personnel were in place. A number of

TABLE 2. Health Care Facility Categories of SARS Exposure

\begin{tabular}{cc}
\hline Category & \multicolumn{1}{c}{ Definition } \\
\hline 0 & $\begin{array}{c}\text { Health care facility has no known cases of SARS } \\
\text { (suspect of probable) } \\
\text { No unprotected SARS exposure-staff and/or } \\
\text { patients; facility could have one or more cases } \\
\text { of SARS (suspect or probable) }\end{array}$ \\
& Any unprotected SARS exposure within the last \\
& 10 days but without transmission to staff or patients; \\
& facility may or may not currently have one or more \\
& cases of SARS (suspect or probable) \\
& Unprotected SARS exposure with transmission to \\
& health care workers and/or patients; facility may or \\
& may not currently have one or more cases of SARS \\
& (suspect or probable)
\end{tabular}




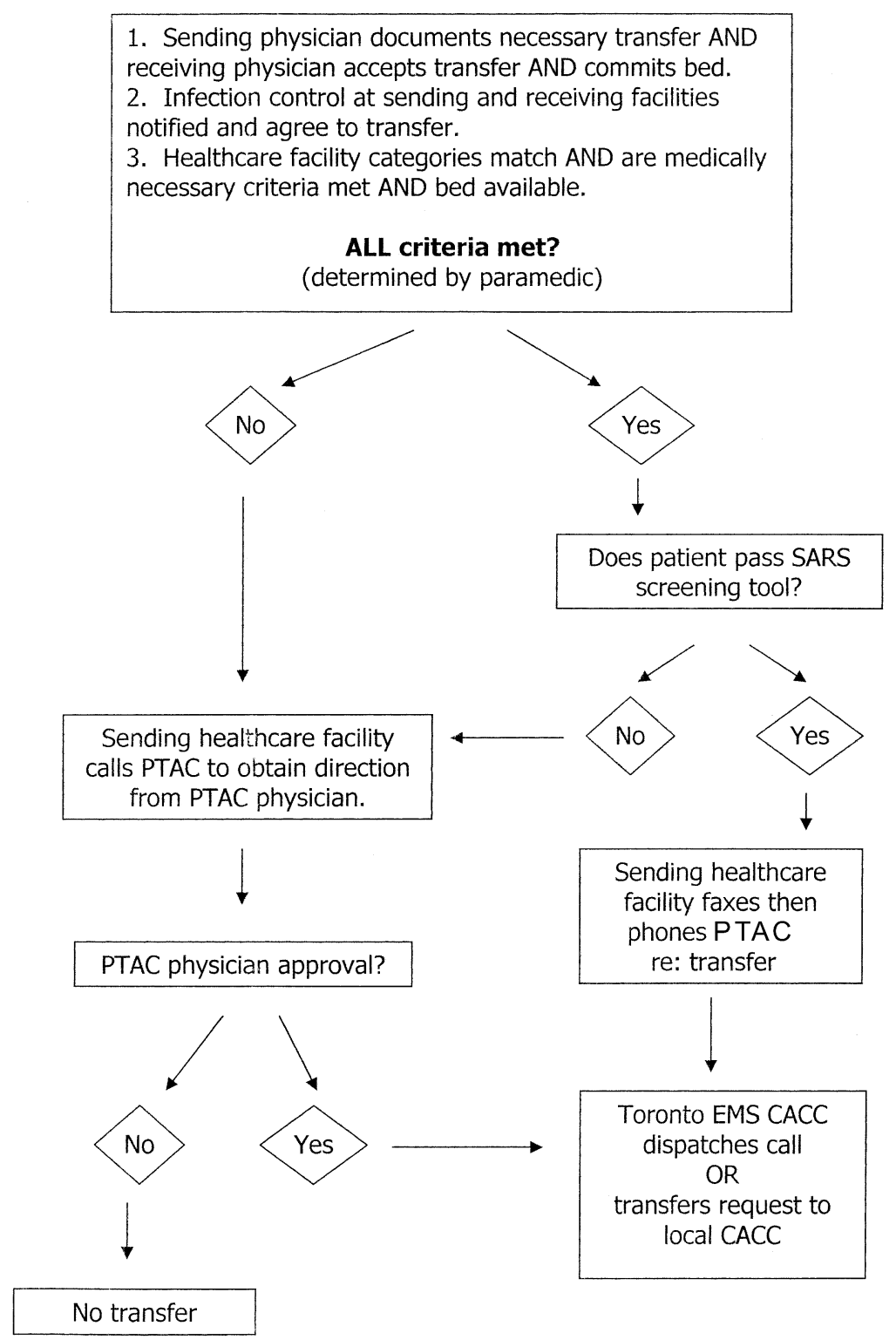

FIGURE 1. Patient transfer decision algorithm.

space, equipment, and staff problems had to be immediately overcome.

The space required for the center was not yet available. Two small offices in the Toronto EMS CACC were quickly modified to accommodate a temporary center. Temporary telephone and facsimile lines were laid along the floor, and equipment was installed on desks and portable tables. Separate offices made face-to-face communication between staff difficult, but locating the temporary center within the existing CACC was essential to permit sharing of existing staff and equipment.

New telephone and facsimile equipment was scheduled to arrive the following day. Support staff located interim equipment elsewhere or purchased it from a local office supply company to meet the center's immediate needs. The temporary telephone and facsimile lines were not equipped with multiple ringdown capabilities to handle simultaneous incoming calls. The lines were call-forwarded to existing CACC telephone lines with multiple ring-down capabilities and then forwarded back to the temporarily installed equipment. This was essential to prevent a busy signal or dropped call.

Managers reassigned paramedic supervisors, dispatchers, and support staff to operate the center. Staff began collating incoming transfer requests, answering telephones, and processing requests based on the decision algorithm (Fig. 1) after only brief introductions to their respective roles. Additional staff was called in 


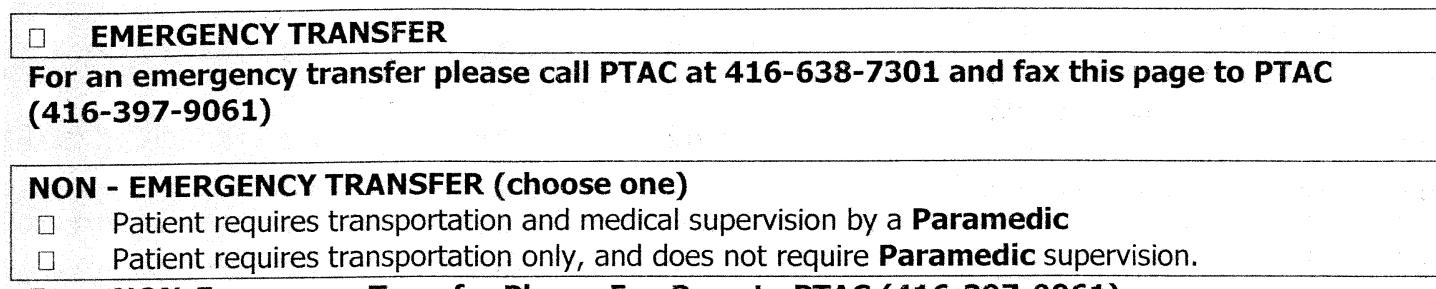

For a NON-Emergency Transfer Please Fax Page to PTAC (416-397-9061)

Requested Transfer Date:

Transfer Time :

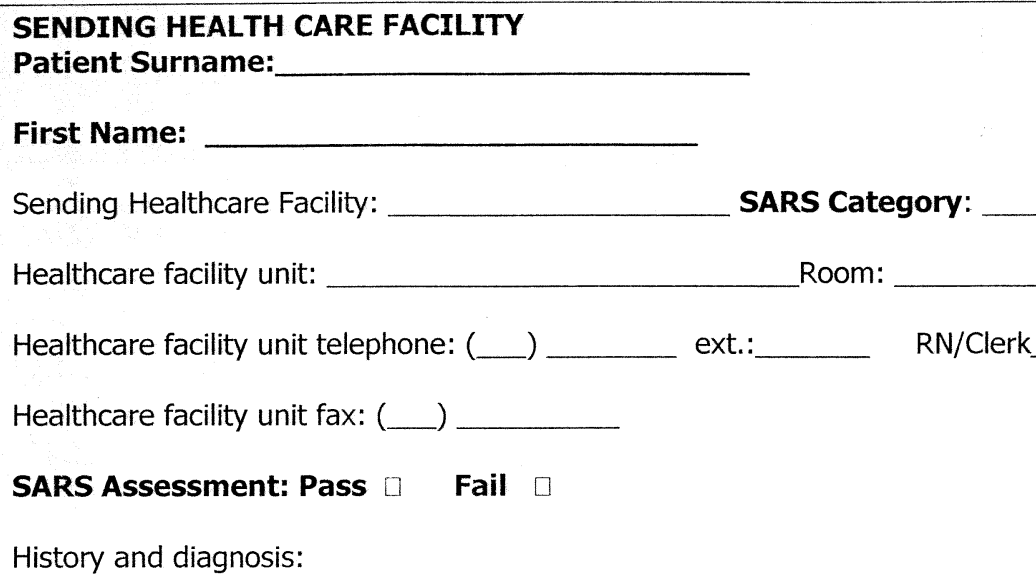

Sending MD Name:

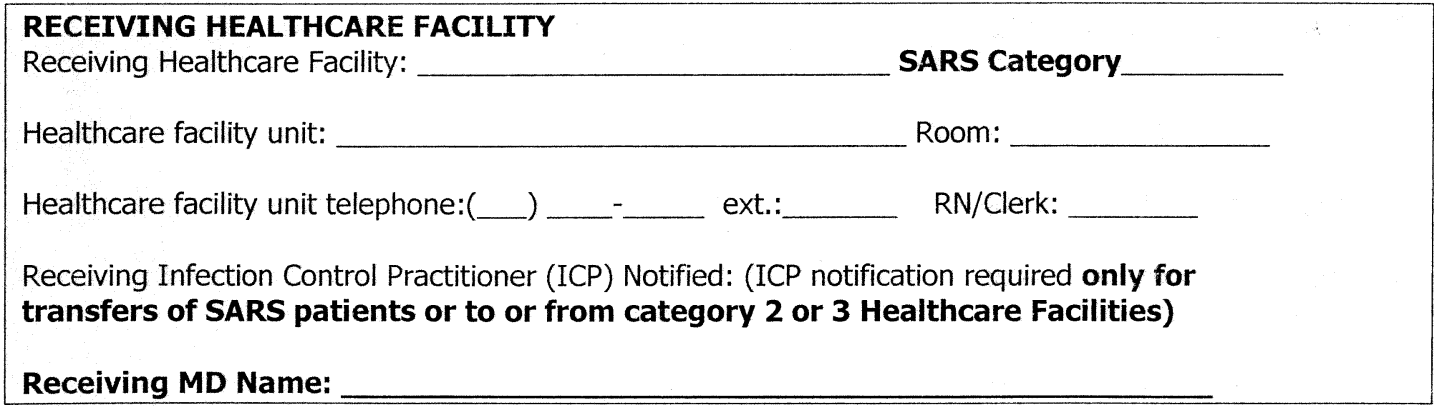

FIGURE 2. Patient transfer authorization form.

to meet increased staffing requirements, and supervisors implemented a schedule based on the anticipated requirements. Two physicians (RDM, BS) were onsite to oversee the PTAC implementation and adjudicate requests that did not meet predetermined criteria until a permanent physician roster was established on April 3.

The working group established the process flow overview, but the details were not developed. Paramedic supervisors, dispatchers, and support staff developed the process flow details on an ad-hoc basis, in real time, in the first few hours after the center was operational. The details underwent continual refinement and were finalized during the first eight to 12 hours (Fig. 3). In less than 36 hours, the center was successfully handling more than 500 requests per day using this detailed process flow.

Infection control measures were also implemented at Toronto EMS headquarters to prevent disruption of essential EMS operations during the SARS outbreak. 
TABle 3. On-duty Staff Requirements in First 48 Hours

\begin{tabular}{lll}
\hline \multicolumn{1}{c}{ Position } & \multicolumn{1}{c}{ Brief Description } & No. Required \\
\hline Supervisor-medical & Oversees and assists screeners & 1 \\
Supervisor-support & Oversees and assists support staff & 1 \\
ALS paramedic screener & Screen requests and approves those meeting all pre-determined criteria & $2-3$ \\
CACC dispatcher & Dispatches approved requests within GTA & 1 \\
Support-call receiver & Receives and assembles incoming requests & 4 \\
Support-call sender & Sends acknowledgment of approved request to sending facility & $3-4$ \\
Support-troubleshooter & Tracks down missing information in received requests & $2-3$ \\
Support-data entry & Maintains request database & $1-2$ \\
Physician & Reviews requests not meeting all predetermined criteria and determines & 1 \\
& suitability for transfer & \\
\hline
\end{tabular}

ALS = advanced life support; CACC = Central Ambulance Communication Center; GTA = Greater Toronto Area.

Access to the Toronto EMS CACC and PTAC was restricted to on-duty staff. All staff had to pass a SARS screening tool similar to those in place at GTA hospitals. As a further precaution, CACC and PTAC staff were not permitted to work in other EMS positions. The precautions were essential to ensure Toronto EMS CACC and PTAC would operate undisrupted by communicable disease during the SARS outbreak.

\section{Expansion and Ongoing Operations}

A permanent center was planned while the temporary PTAC was quickly put into operation. The new $280-\mathrm{m}^{2}$ $\left(3,000-\mathrm{ft}^{2}\right)$ space would accommodate up to 40 staff and process up to 1,500 requests per day. Permanent telephone and facsimile installations began April 2 and were completed within 24 hours. Transition to the new location began April 3 and was completed within 12 hours. A dedicated computer network with facsimile and a database capability was installed and operational by April 7. The temporary center was left in place as a redundant backup until all new systems were tested and functioning properly.

The number of new SARS cases peaked in late March and decreased by mid-April. The volume of interfacility patient transfers increased as more hospitals resumed normal operations. By April 14, the government modified the interfacility patient transfer restrictions to permit nonemergent transfers. The center now handled more than 1,000 transfer requests each weekday. Nonemergent requests were being authorized within 45 to 60 minutes and emergent requests immediately.

An additional 50 staff were recruited, trained, and began work by April 7, bringing the total number of PTAC staff to 80 . By late April, on-duty staffing during peak demand required a minimum of 20 clerical staff, five paramedic supervisors, one manager, and one physician.

When the government lifted its SARS emergency in mid-May, the center was handling more than 1,100 requests each weekday. The volumes remained consistent despite a second SARS outbreak in late May. Figures 4 and 5 illustrate the average number of requests by day of week and time of day, respectively, from May 1 to July 31.

In mid-April, work began on a web-based application to request, process, and authorize patient transfers using the established decision algorithm. The webbased application was implemented on a limited basis at some GTA hospitals on June 16. Although it will not replace the existing paper-based system, an estimated $70 \%$ to $80 \%$ of requests can be processed using the webbased application. This allows health care facilities with web access to receive transfer authorization in minutes. This system will improve throughput and decrease the number of staff required.

The policies, procedures, and formal job descriptions for PTAC operations lagged behind the center's implementation. This was necessary to rapidly develop and implement the center. To ensure long-term operational success, the Ontario Ministry of Health and Long-Term Care will develop the necessary management and oversight infrastructure to meet these needs. The PTAC continues to operate as part of Ontario's commitment as a result of diligence in transport medicine, even though no new cases of SARS were reported since June 12, 2003.

\section{Discussion}

The Greater Toronto Area is the largest metropolitan area outside of Asia to have been impacted by SARS. As of August 15, 2003, there were 375 probable and suspect cases of SARS, with 44 deaths, including three health care workers. ${ }^{6,8}$ In addition, more than 28,000 residents were placed in voluntary ten-day quarantine to prevent the spread of SARS. Exposure to the virus in a health care setting accounted for most SARS cases. No new cases have been reported since June $12,2003 .{ }^{8}$ 


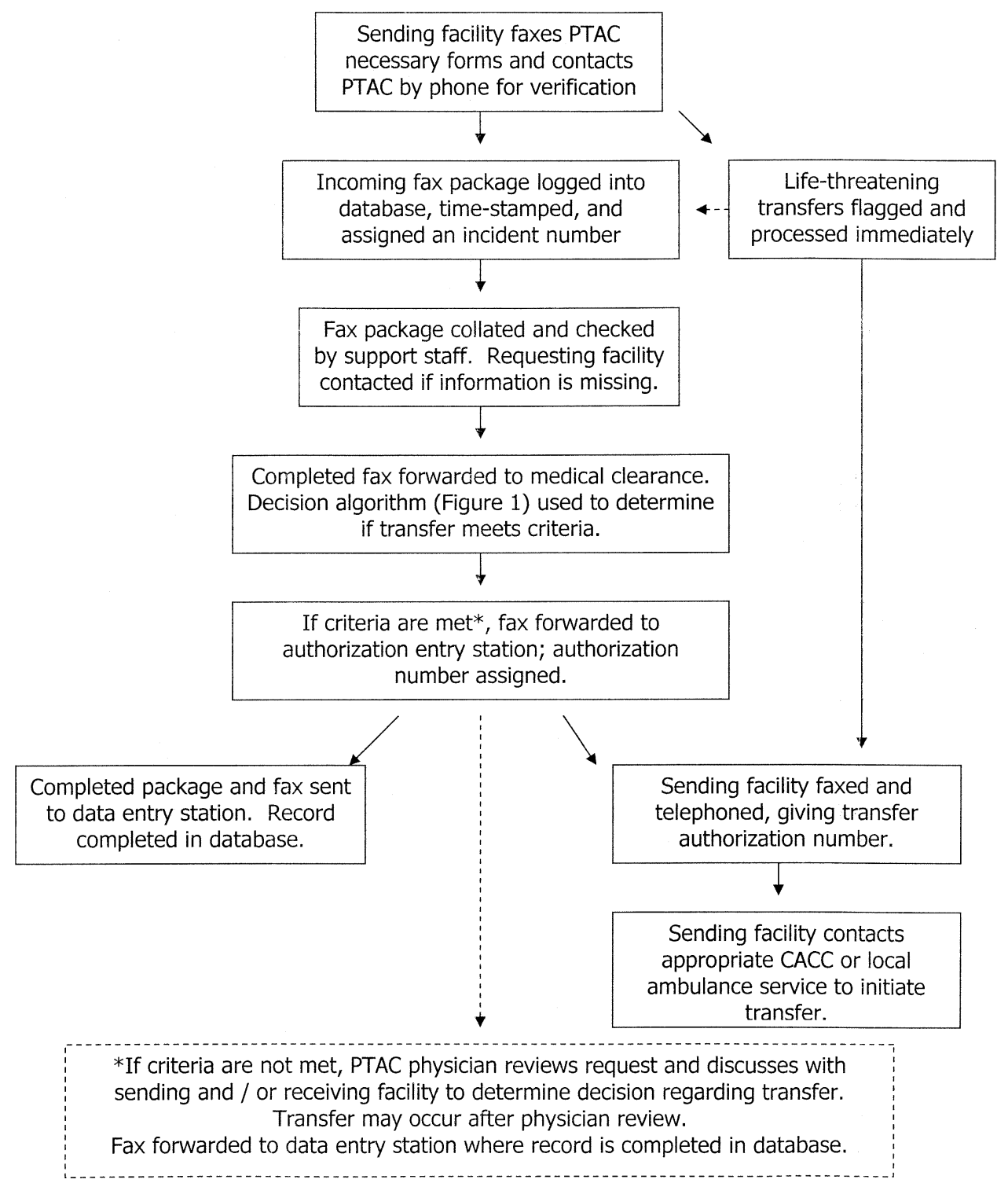

Figure 3. Process flow chart for patient transfer using PTAC.

Ontario's Provincial Transfer Authorization Center is an innovative EMS response to prevent iatrogenic spread of SARS among health care facilities, health care workers, and patients. The center was conceived and implemented in less than 48 hours and reached its anticipated capacity in less than two weeks. It now handles more requests for patient transportation than most EMS dispatch centers in Canada. Rapid development and implementation of a similar EMS-based center have not been previously described. A number of valuable lessons were learned in establishing the PTAC.

The relative success began with a thorough needs assessment with broad stakeholder representation. Input from EMS supervisory and dispatch staff was particularly valuable. Their knowledge of EMS operations changed the working group's initial proposal and assisted with implementation despite the short timelines. They also provided forecasts of daily and peak demand, which, in retrospect, were accurate.

Staff with specific qualifications was selected for each role. Paramedics with advanced life support training could screen requests, interpret the decision algorithm, and approve transfers that did not require physician input. This decision-making ability is well within paramedics' knowledge base and scope of practice, and they function well in the position. Dispatchers were selected to dispatch ambulances or communicate with other CACCs because this was part of their regular duties. Support staff were selected for their existing telephone, facsimile, and data-entry skills. Selecting the appropriate staff is essential to successful 


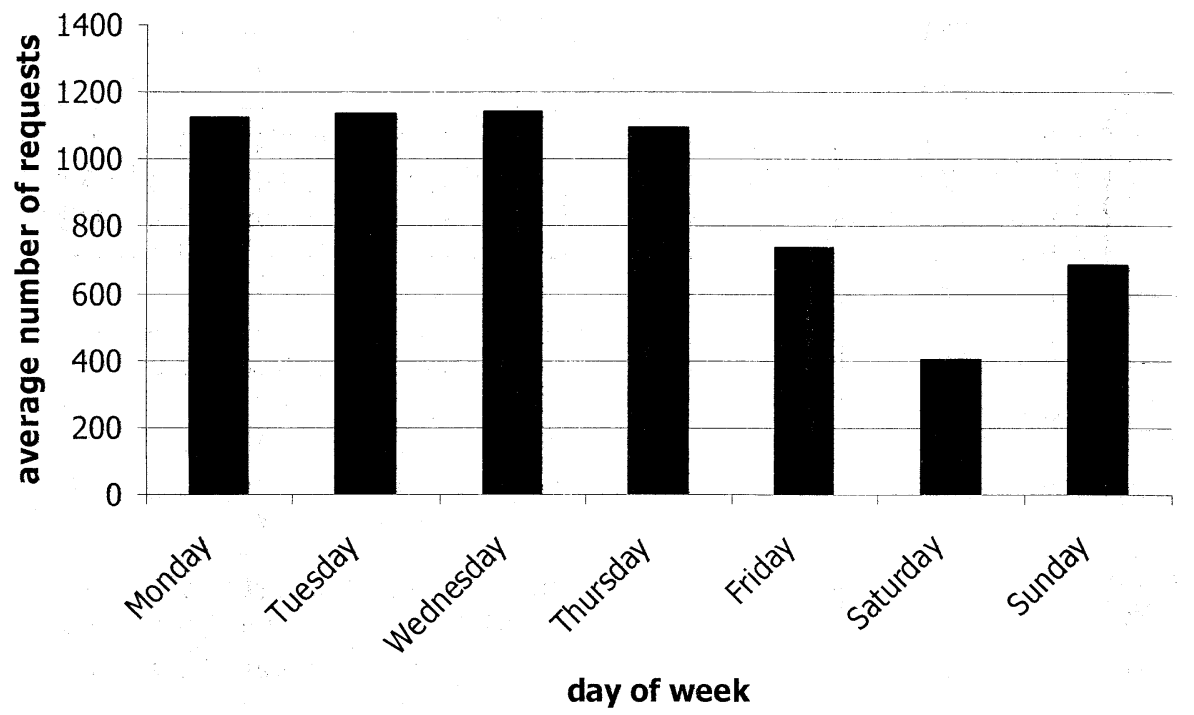

FIGURE 4. Average number of requests for patient transfer by day of week (May-July 2003).

implementation and ongoing improvements in any new EMS operation.

The PTAC was successful because it built on existing systems while being flexible to meet the changing needs during the SARS outbreak. Establishing a new EMS operation using familiar equipment, in a familiar environment, with personnel accustomed to working together contributed to the success. The center's operation was implemented with an untested decisionmaking algorithm and process flow, and no time to orient staff. In retrospect, we believe the added burden of new or unproven technology, in an unfamiliar environment, with staff not used to working together could result in failure.

A rapid transition from the acute emergency to normal operations is essential to minimize the impact of an ongoing emergency. Relocating the center to a permanent location, hiring new staff, and establishing a management infrastructure enabled the center to function independently in a relatively short period of time. Rapid transition minimized the long-term impact on the Toronto EMS CACC, permitting it to return to routine operations in less than five days. Any significant changes to an EMS system must consider its safe implementation so it does not interfere with normal operations for a prolonged period of time.

Significant change requires adequate lead time, clear instructions, and adequate support as the system undergoes change. Implementation of the PTAC directives was problematic. The new transfer approval process was implemented with little advance notice, end-users were unaware of the new process, and

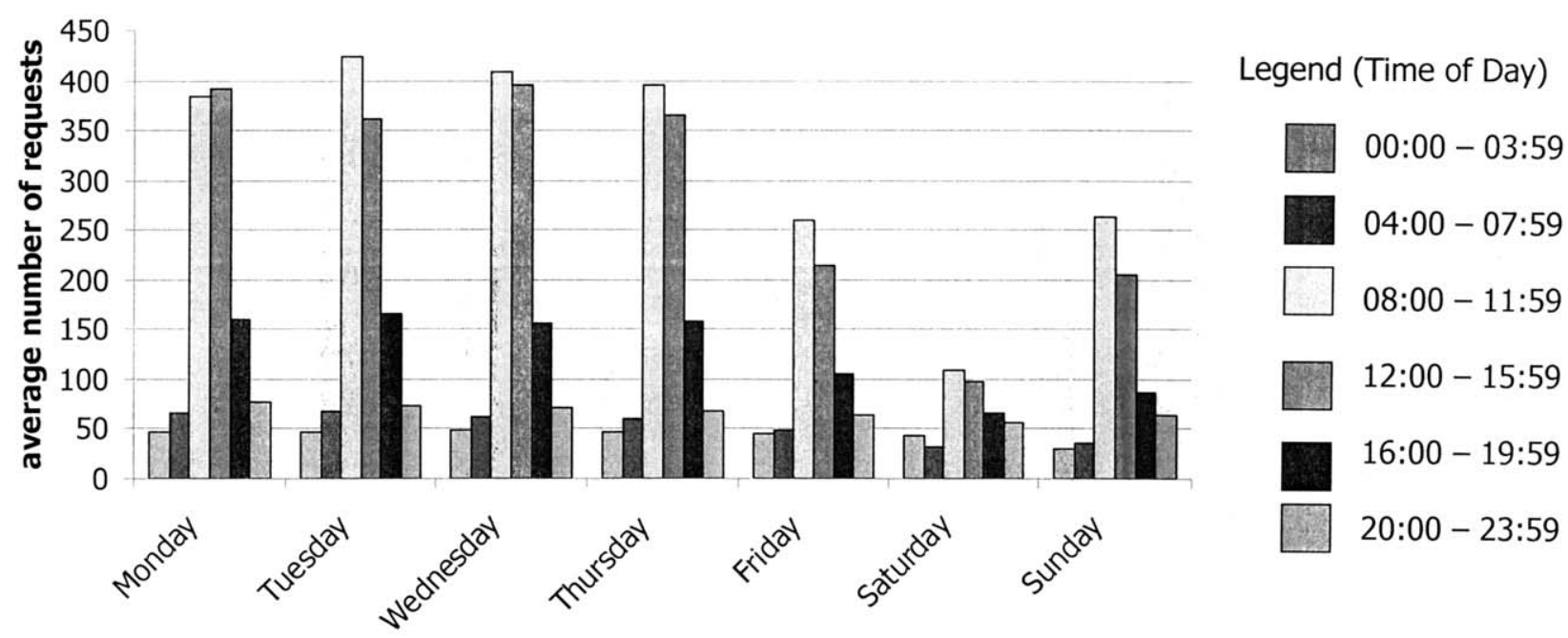

day of week

FIGURE 5. Average number of requests for patient transfer by time of day and day of week (May-July 2003). 
transfer request forms were not readily available. Regional CACCs were aware of the new process but not equipped to handle inquiries from end-users. The working group did not anticipate dissemination problems and did not have adequate staff to answer questions and disseminate transfer request forms. Future implementation of any EMS system change that has large-scale impact on the health care system requires simple written instructions, a better method to disseminate information in a timely manner, and increased staff to manage inquiries from end-users.

The PTAC was implemented to mitigate the risk of iatrogenic spread of SARS as a result of interfacility patient transfers. There was no reported spread of SARS resulting from interfacility patient transfers since the center began operation on April 1, 2003, and anecdotal evidence demonstrates it identified up to 13 new SARS cases during its initial seven weeks of operation (Mazza C, unpublished data, 2003). Further study using SARS case data from public health authorities and PTAC transfer records will determine the center's efficacy at risk mitigation and its impact on Toronto's SARS outbreaks. This investigation is ongoing in collaboration with public health authorities.

An ongoing collaboration between EMS and public health authorities is essential in responding to a threat to population health and well-being. These new working relationships can permit the PTAC to play a significant role in monitoring, detecting, and mitigating risks to public health and the health care system. Given that affected patients could initially present in small numbers in a nonuniform distribution across multiple institutions, a systems-based surveillance system has a greater potential to detect these illnesses when compared with single-institution surveillance systems. Although this type of collaboration is new, an EMS-based system is capable of providing syndromic surveillance in real time ${ }^{9}$ and can provide public health officials with the earliest indication of a potential threat to public health.

\section{Conclusions}

This report describes the innovative EMS command, control, and tracking system established to mitigate the risk of iatrogenic spread of SARS among health care facilities, health care workers, and patients in Ontario as a result of interfacility patient transfers. Rapid establishment of an EMS-based command, control, and tracking center is possible in the setting of a public health emergency. In addition to risk mitigation, this type of center could also be capable of providing syndromic surveillance in real-time and provide the earliest indication of a potential threat to public health.

The authors thank the men and women at Ontario's Provincial Transfer Authorization Center, Toronto EMS, Ontario's Central Ambulance Communication Centers, Ontario's Ministry of Health and Long-Term Care, and the SARS Operations Center for their professionalism, dedication, and hard work during two outbreaks of severe acute respiratory syndrome, and for their ongoing efforts at making Ontario's Provincial Transfer Authorization Center a success. The authors also thank staff in Ontario's health care institutions for their ongoing cooperation with the Provincial Transfer Authorization Center.

\section{References}

1. World Health Organization. Acute Respiratory Syndrome in China. Available at: http://www.who.int/csr/don/2003_02_11/en. Accessed June 21, 2003.

2. World Health Organization. Acute Respiratory Syndrome in China-Update 2. Available at: http://www.who.int/csr/don/ 2003_02_14/en. Accessed June 21, 2003.

3. World Health Organization. Severe Acute Respiratory Syndrome (SARS)—Multi-country Outbreak. Available at: http://www. who.int/csr/don/2003_03_15/en. Accessed June 21, 2003.

4. World Health Organization. Severe Acute Respiratory Syndrome (SARS)—Multi-country Outbreak-Update. Available at: http:// www.who.int/csr/don/2003_03_16/en. Accessed June 21, 2003.

5. Poutanen SM, Low DE, Henry B, et al. Identification of severe acute respiratory syndrome in Canada. N Engl J Med. 2003; 348:1995-2003.

6. Varia M, Wilson S, Sarwal S, et al. Investigation of a nosocomial outbreak of severe acute respiratory syndrome (SARS) in Toronto, Canada. Can Med Assoc J. 2003;169:285-92.

7. Dwosh H, Hong H, Austgarden D, Herman S, Schabas R. Identification and containment of an outbreak of SARS in a community hospital. Can Med Assoc J. 2003;168:1415-20.

8. World Health Organization. Summary Table of SARS Cases by Country, 1 November 2002-7 August 2003. Available at: http:// www.who.int/entity/csr/sars/country/en/crountry/2003_08_ 15.pdf. Accessed August 16, 2003.

9. Greenko J, Mostashari F, Fine A, Layton M. Clinical evaluation of the emergency medical services (EMS) ambulance dispatch-based syndromic surveillance system, New York City. J Urban Health. 2003;80(suppl 1):I50-6. 